Document downloaded from:

http://hdl.handle.net/10251/104231

This paper must be cited as:

Blay-Roger, V.; Miguel, PJ.; Corma Canós, A. (2017). Theta-1 zeolite catalyst for increasing the yield of propene when cracking olefins and its potential integration with an olefin metathesis unit. Catalysis Science \& Technology. 7(4):5847-5859. doi:10.1039/c7cy01502j

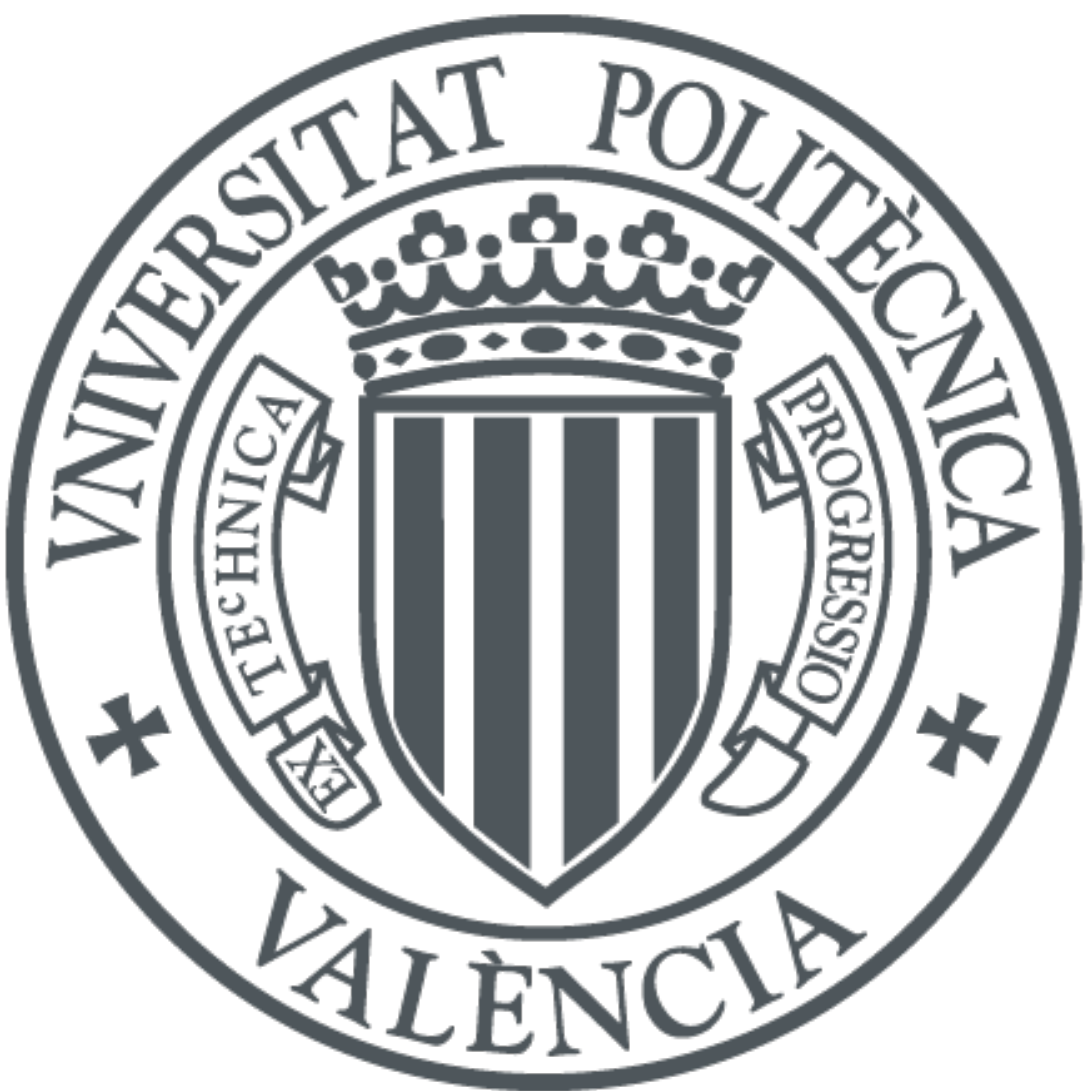

The final publication is available at

http://dx.doi.org/10.1039/c7cy01502j

Copyright The Royal Society of Chemistry

Additional Information 


\title{
Zeolite Catalyst for increasing the yield of propene when cracking olefins and its potential integration with an olefin metathesis unit
}

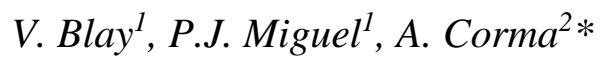 \\ ${ }^{1}$ Departamento de Ingeniería Química, Universitat de València, Av. de la Universitat, \\ s/n, 46100 Burjassot, Spain \\ ${ }^{2}$ Instituto de Tecnología Química, Universitat Politècnica de València-Consejo Superior \\ de Investigaciones Científicas, Avenida de los Naranjos s/n, 46022 Valencia, Spain \\ *Corresponding author acorma@itq.upv.es
}

Draft for submission to Catalysis Science \& Technology

\begin{abstract}
There is a need for on purpose propene production technologies beyond energy-intensive steam cracking. Hexene is a compound with limited value that can be found in several streams in the refinery, and can readily crack on zeolites at lower temperatures and shorter contact times than those used for cracking alkanes. Cracking over ZSM-5 zeolite yields high selectivity to light olefins. These results are improved by Theta-1 zeolite, which can yield a remarkable propene molar selectivity of $180 \%$ (90 wt.\%) at $90 \%$ conversion, close to the maximum thermodynamic yield. Moreover, crystal engineering allowed increasing its TOF by more than $50 \%$. Based on these results we also identified some prospective applications of Theta-1 zeolite as a catalyst for an integrated process directed to maximize propene.
\end{abstract}

Keywords: propene, olefin cracking, zeolite, ZSM-5, Theta-1, postsynthesis, FCC, metathesis 


\section{Introduction}

Short chain olefins (ethene, propene and butenes) are the main feedstocks for the petrochemical industry. Propene is being produced at around 100 MMTA (1) and its demand is predicted to grow strong, at around $4.5 \%$ p.a., which is $0.7 \%$ higher than the average annual growth rate for ethene (2). As it is also the case for ethene, propene is mainly used to produce polymers, such as polypropene, acrylonitrile, polyesters and polyurethanes, as well as acetone via cumene.

It is important to note that, differently from ethene, propene has traditionally been obtained as a by-product of fluid catalytic cracking (FCC) and steam cracking of naphtha. Many of new and existing FCC units are being designed or revamped to yield more propene, mainly by operating at higher severity (increased cat-oil ratios and temperatures) and by incorporating more catalyst additive based on ZSM-5 zeolite, in addition to changes in design such as dual riser configurations or downer reactors $(3,4)$. However, with the current trend in fuels towards diesel and ethanol and a shift in steam cracking to process shale gas-derived feedstocks, conventional units cannot satisfy the increasing demand of propene, in spite of the recent decline in oil prices.

As a result, on purpose propene technologies, such as propane dehydrogenation (PDH), methanol to olefins (MTO) or metathesis of olefins, are being increasingly implemented. This on purpose propene production is forecasted to grow from 17 MMTA in 2014 to 42 MMTA in 2019 according to IHS (2). Table 1 compares some of these technologies. Selectivity to propene by steam cracking is strongly conditioned by the feed, whereas technologies such as PDH or MTO, although potentially very selective, also require high investments to benefit from economies of scale. Adjusting the composition of the FCC catalyst inventory is a more immediate but limited action to 
obtain some gain in propene production. In this line, metathesis of olefins also requires a comparably small investment, although the economics may be tight as valuable ethene is consumed along with butenes. Cracking of medium chain length olefins may be an interesting option, especially if high catalyst selectivity and stability are achieved, as we discuss in this work. Among other research lines to produce propene, one can identify efforts to produce it from bio-derived feedstocks, such as acetic acid (5).

Table 1. Comparison of selected propene production technologies.

\begin{tabular}{|c|c|c|c|c|}
\hline Technology & Temperature $/{ }^{\circ} \mathbf{C}$ & Pressure / bar & Propene selectivity & Cost \\
\hline Steam cracking & $750-900$ & $2-3$ & $1-14$ wt. $\%^{c}$ & High \\
\hline FCC & 550 & $1-2$ & $4-6$ wt. $\%$ & Medium \\
\hline $\mathrm{FCC}+\mathrm{ZSM}-5$ & $560-600$ & $1-2$ & $7-10$ wt. $\%$ & Medium $^{\mathrm{d}}$ \\
\hline HS-FCC & 600 & $1-2$ & 20 wt. $\%$ & Medium \\
\hline $\mathrm{PDH}$ & $540-700$ & $0.1-4$ & Up to $100 \mathrm{wt} . \%$ & High \\
\hline МТO, МТР & $350-500$ & 1 & Up to 80 wt. $\%$ & High \\
\hline Olefin metathesis & $\begin{array}{l}\text { 25-50 (Re-alumina) } \\
\left.\text { 300-375 ( } \mathrm{WO}_{3} \text {-silica }\right)\end{array}$ & $5-15$ & Up to 100 wt. $\%$ & Low $^{\mathrm{e}}$ \\
\hline Olefin cracking ${ }^{\mathrm{a}}$ & $400-550$ & 1 & Up to 90 wt. $\%$ & Low \\
\hline $\begin{array}{c}\text { Hydrogenation of acetic } \\
\text { acid }^{\mathrm{b}}\end{array}$ & $300-450$ & $1.2-4$ & 50 wt. $\%$ & - \\
\hline
\end{tabular}

${ }^{\text {aPresent work. }}{ }^{\mathrm{b}}$ Patented but not-commercialized. ${ }^{\mathrm{c}}$ Feed dependent $1 \mathrm{wt} . \%$ from ethane, $14 \mathrm{wt} . \%$ for naphtha. ${ }^{\mathrm{d}}$ Low cost for existing units but limited improvements. ${ }^{\mathrm{e}}$ Requires ethene, which limits margins.

The number of research articles devoted to producing more propene from cracking has increased in the last years. On the one hand, there has been an increasing number of publications in which new zeolite structures were explored as cracking catalysts or additives, such as zeolite Y, Beta, MCM-22, ZSM-5, ZSM-22, ZSM-23, ZSM-35, IM-5, ferrierite or SAPO-34 (6-13). On the other hand, highly olefinic streams have been 
recognized as a suitable feed to increase propene production by catalytic cracking, particularly the cracking of butene $(14-18)$, but also pentene $(19,20)$, hexene $(21,22)$ or octene (23).

In this work we present results of 1-hexene cracking over selected zeolite materials: ZSM-5 zeolites of high and low aluminum content, and Theta-1 zeolite. The materials have been tested at low and intermediate olefin partial pressure to study its effect on the kinetics and selectivity. We thus attempted to model the kinetic results observed and to relate them to the underlying reaction mechanism. Remarkably, we found that Theta-1 material yields an excellent selectivity to propene in the cracking of 1-hexene. Taken together, these results could contribute to the implementation of novel zeolite catalysts at the industrial scale, for which we also propose some possibilities at the end of the article.

\section{Experimental}

\subsection{Materials}

1-hexene ( $\geq 99 \%$ ) was acquired from Sigma Aldrich and cracked without further purification. He (99.999 \% purity) was supplied by Carburos Metálicos (Air Products and Chemicals) and used as diluent. Three zeolite catalyst samples were investigated in this work: CBV-3024E, CBV-28014 and Theta-1. Samples CBV-3024E and CBV28014 are commercial ZSM-5 zeolites acquired from Zeolyst International with nominal $\mathrm{Si} / \mathrm{Al}$ ratios of 15 and 140, respectively. Catalyst Theta-1 is a zeolite with TON structure and a $\mathrm{Si} / \mathrm{Al}$ ratio of 44 . A sample of Theta-1 material was subjected to postsynthesis treatment with a $0.5 \mathrm{M} \mathrm{NaOH}$ solution (solution/solid mass ratio of 33) at 
$85{ }^{\circ} \mathrm{C}$ for 30 min under vigorous stirring, followed by quenching in an ice bath. The sample was filtrated, washed and dried overnight at $100{ }^{\circ} \mathrm{C}$. It was then ion-exchanged in a $2.0 \mathrm{M}$ oxalic acid solution (solution/solid mass ratio of 10 ) at $70{ }^{\circ} \mathrm{C}$ for $2 \mathrm{~h}$. This catalyst will be referred to as treated Theta-1.

\subsection{Characterization}

Catalyst structure and crystallinity was confirmed by powder X-ray diffraction in a Panalytical Cubix diffractometer with Bragg-Brentano geometry, using $\mathrm{CuK}_{\alpha}$ radiation and an $\mathrm{X}^{\prime}$ Celerator detector. The X-ray tube was operated at $45 \mathrm{kV}$ and $40 \mathrm{~mA}$ with automatic divergence slits for a constant irradiated length of $2.5 \mathrm{~mm}$. Measurements were performed from $2^{\circ}$ to $40^{\circ}(2 \theta)$ in steps of $0.020^{\circ}(2 \theta)$ and a counting time of $35 \mathrm{~s}$ per step. The obtained diffraction patterns (Fig. S1) are in agreement with those reported for the corresponding idealized frameworks (24).

Textural properties of the samples were studied by nitrogen adsorption isotherms at 77 K with a Micromeritics ASAP 2010 volumetric instrument. Samples were outgassed in situ overnight at $10^{-6} \mathrm{~Pa}$ and $400{ }^{\circ} \mathrm{C}$ prior to measurements. Specific surface area was derived from the BET model. Micropore volume was assessed using the t-plot method in which the statistical thickness was described with the Harkins-Jura equation for nonporous $\mathrm{Al}_{2} \mathrm{O}_{3}$. Mesopore volume was derived from the adsorption isotherm employing the BJH model. Results of these analyses are presented in Table S1. The samples were also investigated with a Jeol JSM-6300 scanning electron microscope at an acceleration voltage of $30 \mathrm{kV}$ (Fig. S2). These had been previously sputter coated with $\mathrm{Au}$ in a BAL-TEC SCD 005 apparatus for $90 \mathrm{~s}$. Theta-1 materials were further observed without coating in a ZEISS Ultra 55 field-emission scanning electron microscope at an acceleration voltage of $1 \mathrm{kV}$ and a working distance of $4.3 \mathrm{~mm}$. 
Chemical composition of the samples was determined by ICP-AES with a Varian 715ES instrument. $30 \mathrm{mg}$ of the samples were dissolved in $5 \mathrm{ml}$ of a 1:1:3 $\mathrm{HF} / \mathrm{HNO}_{3} / \mathrm{HCl}$ solution, subsequently diluted to $65 \mathrm{ml}$ and fed to the instrument. Acidity of the zeolites was assessed by FTIR spectroscopy of adsorbed pyridine with a Nicolet iS10 instrument. Self-supported catalyst wafers $\left(8 \mathrm{mg} \mathrm{cm}^{-2}\right)$ were loaded in a glass cell with $\mathrm{CaF}_{2}$ windows and activated at $400{ }^{\circ} \mathrm{C}$ under vacuum $\left(10^{-2} \mathrm{~Pa}\right)$. The samples were cooled at room temperature and blank spectra were recorded. Pyridine was then admitted (1.9 $\mathrm{kPa})$ until equilibration. Desorption was performed at 150, 250 and $350{ }^{\circ} \mathrm{C}$ for $1 \mathrm{~h}$ periods, followed by measurement of the IR absorption spectra at room temperature (Fig. S3). Spectra were normalized by sample weight, and integral absorption coefficients were taken from (25) for bands around 1540 and $1450 \mathrm{~cm}^{-1}$, assigned to Brønsted and Lewis acid sites, respectively (Table S2).

\subsection{Catalytic tests}

The catalysts were studied in a fixed bed reactor system. The reactor was made of quartz glass, measuring $300 \mathrm{~mm}$ long and $11 \mathrm{~mm}$ i.d., and contained a coaxial thermocouple sensing the temperature in the center of the catalytic bed. The catalyst was diluted with silicon carbide to a constant volume of $1.5 \mathrm{ml}$. SiC helps homogenizing the temperature of the bed thanks to its thermal conductivity and favors approximation to plug flow. Catalysts were pressed under a uniaxial stress of $2000 \mathrm{~kg}$ $\mathrm{cm}^{-2}$, which PXRD confirmed as appropriate, and were later sieved to $0.3-0.5 \mathrm{~mm}$ particle size.

Catalysts were heated before reaction in a stream of $\mathrm{He}$ at a rate of $1{ }^{\circ} \mathrm{C} \min ^{-1}$ up to 550 ${ }^{\circ} \mathrm{C}$ and maintained at this temperature for $1 \mathrm{~h}$. Reactions were conducted at a total absolute pressure of 1.06 bar and a temperature of $500{ }^{\circ} \mathrm{C}$ using helium as an inert 
diluent. He flow was set depending on the desired feed partial pressure while maintaining the total feed flow. The contribution of thermal cracking in the absence of catalyst was found negligible $(<2 \%)$. 1-hexene was fed to an evaporator system using a syringe pump (Braun Secura FT). The evaporator temperature was adjusted to ensure a constant vaporization rate.

Analyses of the reactor effluent were performed using a gas chromatograph using helium as carrier gas. The reactor effluent is sampled by two heated multiloop valves in parallel, which allow sampling volumes of $0.25 \mathrm{ml}$ at the desired TOS values for later analysis by the GC. The multiloop valves feed two GC channels, comprising a $2 \mathrm{~m} \mathrm{x}$ 1/8” Porapak Hayesep D 80/100 column and a TCD, and a $100 \mathrm{~m}$ x $0.25 \mathrm{~mm}$ x $0.5 \mu \mathrm{m}$ Petrocol DH column and a FID. Results in this work correspond to initial cracking rates $(\mathrm{TOS}=0 \mathrm{~s})$.

\subsection{Calculations}

Kinetic modelling was carried out on Matlab $^{\circledR} 9.1 .0$ as custom made scripts. In particular, the solver ode 45 was used to integrate the mass balance along the reactor when power law kinetics were considered. It is based on an adaptive Runge-Kutta method of orders 5 and 4 (Dormand-Prince). The routine nlinfit was used to adjust the model parameters and to estimate their standard error. It is a finely coded version of the Levenberg-Marquardt nonlinear least squares algorithm. The objective function thus minimized was:

$$
\text { O.F. }=\sum\left(\mathrm{X}_{\text {observed }}-\mathrm{X}_{\text {computed }}\right)^{2}
$$




\section{Results and discussion}

\subsection{Cracking kinetics}

Fig. 1 presents the evolution of 1-hexene initial conversion with contact time on the different catalysts studied at two different olefin partial pressures. Conversion is defined as the percent moles of 1-hexene that are converted to products different from hexenes. It can be observed that the order of catalytic activity follows the sequence CBV-3024E

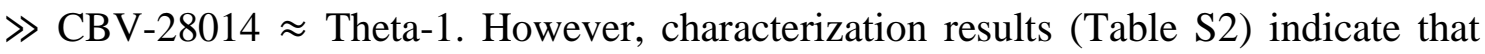
acid site density follows the order CBV-3024E > Theta-1 > CBV-28014. It appears that, besides acidity, another factor must also be playing a role. In addition, notice that reaction rates for olefin cracking are very fast compared to the cracking of alkanes and thus much shorter contact times $\left(\mathrm{WHSV}^{-1}\right)$ can be used to attain comparable conversions when cracking olefins (26). It can be observed that conversion and therefore reaction rate increase at a given $\mathrm{WHSV}^{-1}$ when partial pressure is increased. 

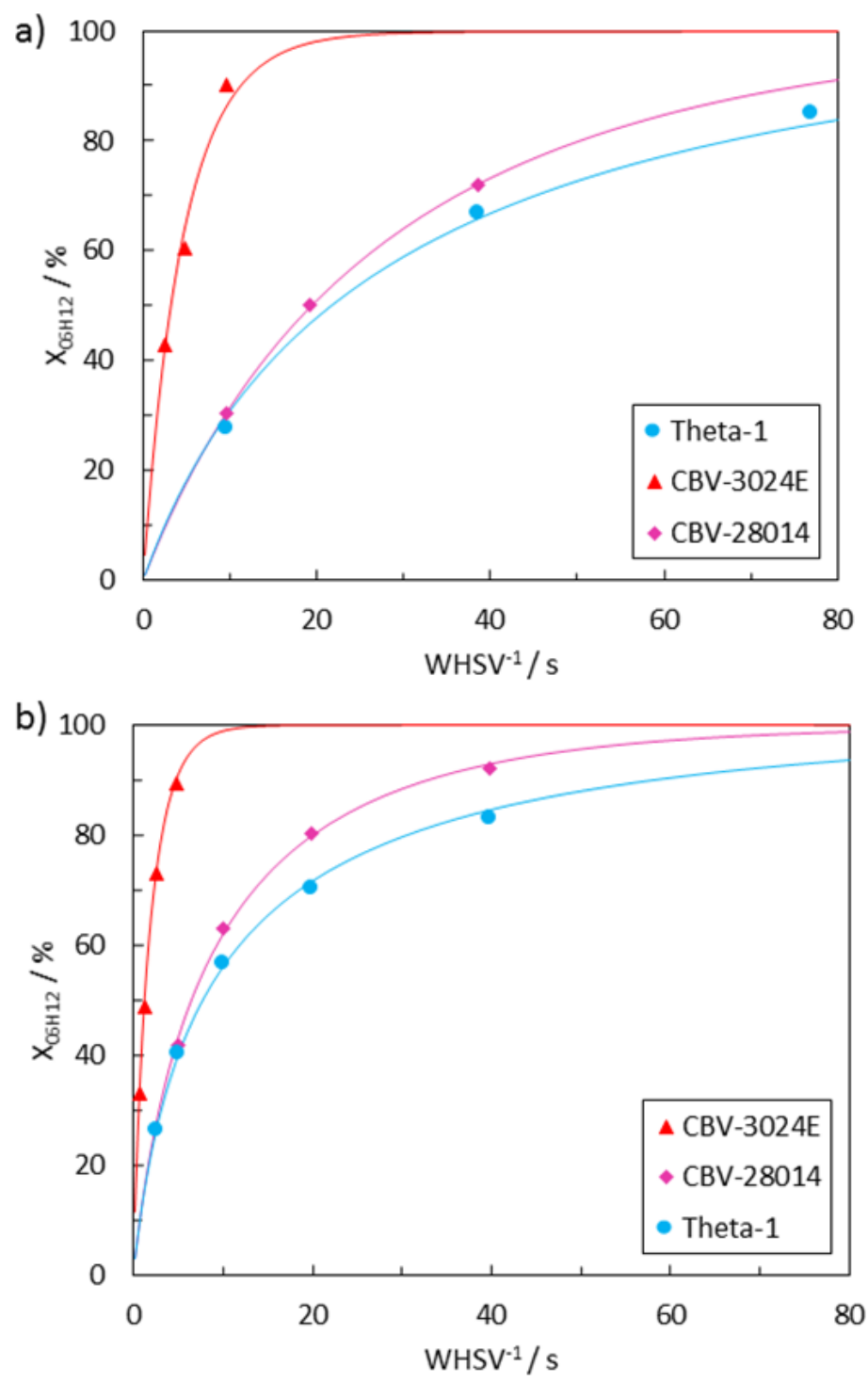

Figure 1. Initial conversion of 1-hexene vs. contact time on selected zeolites at a) low $\left(\mathrm{x}_{0}=0.065\right)$, and $\left.\mathrm{b}\right)$ intermediate $\left(\mathrm{x}_{0}=0.251\right)$ feed partial pressures.

We attempted to model these kinetic results, as they might provide information to discuss the reaction mechanism. Since a differential reactor cannot be assumed when operating at medium and high conversions, the mass balance equation was integrated along the reactor length:

$$
\mathrm{WHSV}^{-1}=\frac{1}{\mathrm{M}_{\mathrm{A}}} \int_{0}^{\mathrm{X}} \frac{\mathrm{dX}}{\mathrm{r}}
$$

For the rate expression, as a first approximation, we propose a first order model: 


$$
\mathrm{r}=\mathrm{k}_{1} \cdot \mathrm{p}_{\mathrm{A}}=\mathrm{k}_{1} \cdot\left(\mathrm{p}_{\mathrm{A} 0} \frac{1-\mathrm{X}}{1+\varepsilon \cdot \mathrm{X}}\right)
$$

Notice that, since there is a change in the number of moles during the reaction, we take into account a volumetric expansion factor, $\varepsilon$. This expansion factor is proportional to the molar fraction in the feed, $\mathrm{x}_{0}$, and to the observed increase in the number of moles upon reaction, $\delta$ :

$$
\varepsilon=\mathrm{x}_{0} \cdot \delta
$$

Ideally, for an olefin cracking reaction $\delta$ would equal 1, since two molecules are formed as a result of cracking one molecule, resulting in a net increase of one molecule. In practice, however, other factors make this value differ from 1: re-cracking reactions, on the one hand, would tend to increase this value, whereas hydrogen transferaromatization reactions, on the other hand, can decrease $\delta$. In the range studied for olefin cracking a value of $\delta$ around $0.85-0.95$ was found experimentally, as the extent of re-cracking is minimal at the short contact times employed.

Inserting eq. 3 into eq. 2 and integrating along the reactor yields the following relationship:

$$
-\mathrm{k} \cdot \tau_{\mathrm{W}}=(1+\varepsilon) \cdot \ln (1-\mathrm{X})+\varepsilon \cdot \mathrm{X}
$$

where $\tau_{\mathrm{W}}=\mathrm{p}_{\mathrm{A} 0} \cdot \mathrm{WHSV}^{-1} \cdot \mathrm{M}_{\mathrm{A}}$ is the modified contact time (27). Therefore, if the kinetic results are truly first order and $\varepsilon$ is small, given $\tau_{\mathrm{W}}$ a certain conversion will be observed, irrespective of the partial pressure of the reactant in the feed. In Fig. S4 conversion is plotted as a function of $\tau_{\mathrm{W}}$. We can see that there is a better overlapping between series at both feed partial pressures than when they are represented as a function of $\mathrm{WHSV}^{-1}$ (Fig. 1), indicating that first order kinetics is a good approximation 
to the behavior observed. However, a weak dependence on partial pressure is still observed, especially at long $\tau_{\mathrm{W}}$.

Thus, we have also explored a more flexible power law model:

$$
\mathrm{r}=\mathrm{k}_{\mathrm{n}} \cdot \mathrm{p}_{\mathrm{A}}{ }^{\mathrm{n}}=\mathrm{k}_{\mathrm{n}} \cdot\left(\mathrm{p}_{\mathrm{A} 0} \frac{1-\mathrm{X}}{1+\varepsilon \cdot \mathrm{X}}\right)^{\mathrm{n}}
$$

which was also inserted into eq. 2 and integrated numerically. Table 2 presents the results of fitting the two models to the data. It can be observed that the power law models converged to apparent reaction orders very close to but below 1 . In the Supporting Information a discussion is provided on external transport, internal transport and reaction equilibrium (Table S3). It is concluded that diffusional limitations may become relevant in the cracking of hexene over these zeolites, especially internal (intraparticle) diffusion limitations in low $\mathrm{Si} / \mathrm{Al}$ ratio zeolite pellets (CBV-3024E). This is a consequence of hexene being much more reactive than the more common alkanes. Even if external and internal mass transfer limitations can have an important effect on heterogeneous catalysts, additional experiments on CBV-3024E varying the total flow and the size of pellet did not result in noticeable changes in selectivity at a given conversion. This may be because zeolite pellets possess a bimodal distribution (28) and most of their active surface is intracrystalline (Table S1). Reduced efficiency due to external diffusion limitations or internal diffusion limitations in the macro- and mesopores between crystals are unlikely to affect the observed selectivities significantly. On the one hand, the utilization of the different catalysts is not alarmingly inefficient, and in fact could be in a range appropriate for industrial application (29). Moreover, in practice, technical catalysts are composed of several ingredients and therefore the concentration of the zeolite in the catalyst could be optimized, too (30). On the other hand, thermodynamic limitations may also lower the reaction rate of hexene, 
especially at high conversion levels. An equilibrium involving hexene would not be reached, though, as secondary reactions of aromatization, hydrogen transfer and light olefin interconversion occur in real experiments and would eventually push its conversion to virtually $100 \%$.

Table 2. Results of nonlinear regression of hexene conversion to the proposed models.

\begin{tabular}{|c|c|}
\hline \multicolumn{2}{|c}{ CBV-3024E } \\
\hline First order & Power law model \\
\hline $\mathrm{k}_{1}=32.7 \pm 3.0$ & $\begin{array}{c}\mathrm{k}_{\mathrm{n}}=16.0 \pm 2.7 \\
\mathrm{n}=0.74 \pm 0.06\end{array}$ \\
\hline $\mathrm{RMSE}=0.0721$ & $\mathrm{RMSE}=0.0385$ \\
$\mathrm{R}^{2}=0.8937$ & $\mathrm{R}^{2}=0.9696$ \\
\hline
\end{tabular}

\begin{tabular}{|c|c|}
\hline \multicolumn{2}{|c}{ CBV-28014 } \\
\hline First order & Power law model \\
\hline $\mathrm{k}_{1}=5.33 \pm 0.39$ & $\begin{array}{c}\mathrm{k}_{\mathrm{n}}=3.8 \pm 1.0 \\
\mathrm{n}=0.87 \pm 0.10\end{array}$ \\
\hline $\mathrm{RMSE}=0.0511$ & $\mathrm{RMSE}=0.0453$ \\
$\mathrm{R}^{2}=0.9368$ & $\mathrm{R}^{2}=0.9504$ \\
\hline
\end{tabular}

\begin{tabular}{|c|c|}
\hline \multicolumn{2}{|c}{ Theta-1 } \\
\hline First order & Power law model \\
\hline $\mathrm{k}_{1}=4.24 \pm 0.42$ & $\begin{array}{c}\mathrm{k}_{\mathrm{n}}=4.5 \pm 1.6 \\
\mathrm{n}=1.02 \pm 0.14\end{array}$ \\
\hline $\mathrm{RMSE}=0.0716$ & $\mathrm{RMSE}=0.0715$ \\
$\mathrm{R}^{2}=0.9066$ & $\mathrm{R}^{2}=0.9069$ \\
\hline
\end{tabular}

\begin{tabular}{|c|c|}
\hline \multicolumn{2}{|c}{ Treated Theta-1 } \\
\hline First order & Power law model \\
\hline $\mathrm{k}_{1}=7.14 \pm 0.56$ & $\begin{array}{c}\mathrm{k}_{\mathrm{n}}=5.2 \pm 1.5 \\
\mathrm{n}=0.88 \pm 0.11\end{array}$ \\
\hline $\mathrm{RMSE}=0.0606$ & $\mathrm{RMSE}=0.0552$ \\
$\mathrm{R}^{2}=0.8268$ & $\mathrm{R}^{2}=0.8562$ \\
\hline
\end{tabular}

\subsection{Selectivity}

Theta-1 zeolite leads to a very interesting product slate. Main yields to light olefins are displayed in Fig. 2 as a function of conversion for an intermediate value of hexene partial pressure in the feed $\left(\mathrm{x}_{0}=0.251\right)$. Molar yield to a product is defined as the number of moles produced by moles of olefin fed. Similarly, molar selectivity to a product is defined as the number of moles produced by moles of olefin reacted. Remarkably, Theta-1 zeolite yields propene with a molar selectivity over $160 \%$ with some ethene and butenes co-produced. Notably, selectivity to propene on Theta-1 exceeds in all cases the selectivities achieved by commercial ZSM-5 zeolites. Fig. S6 
shows the yields to light olefins upon cracking at a lower partial pressure $\left(\mathrm{x}_{0}=0.065\right)$. At this lower partial pressure, a molar selectivity to propene of $180 \%$ at a hexene conversion over $90 \%$ has been achieved.

A more detailed distribution of products upon reaction is summarized in Table 3 for intermediate feed partial pressure and in Table $\mathrm{S} 4$ for low feed partial pressure. The extent of hydrogen transfer (HT) reactions is remarkably low on Theta-1 material compared to ZSM-5, which yields more alkanes and BTX. Notice also that these HT products are produced at a greater extent as partial pressure is increased, particularly on ZSM-5 samples, evidencing its formation through bimolecular reactions of the primary products of cracking.

Fig. 3 presents the propene to ethene molar ratio (P/E) obtained upon cracking of 1hexene as a function of the propene partial pressure at the reactor outlet. This ratio is very high with Theta-1 zeolite cracking catalyst, exceeding values higher than 25 at conversions up to $56 \%$. The $\mathrm{P} / \mathrm{E}$ ratio is much lower with ZSM-5 catalysts, with values below 5 for cracking on the CBV-3024E commercial sample even at only $33 \%$ conversion. Interestingly, the P/E ratio can be substantially improved using the ZSM-5 catalyst with a higher $\mathrm{Si} / \mathrm{Al}$ ratio. This could be related to its acidity and geometry, as will be discussed below. In addition, P/E ratios obtained under our operating conditions are conveniently much greater than the corresponding equilibrium ratios. One can also observe that, as contact time (and hence hexene conversion and propene partial pressure) is increased, the $\mathrm{P} / \mathrm{E}$ ratio decreases towards the equilibrium value. This diminution is delayed to longer contact times over Theta-1 zeolite. Fig. S7 presents the $\mathrm{P} / \mathrm{E}$ ratio at lower olefin partial pressure from which similar conclusions can be drawn. On the other hand, Fig. S8 presents the propene to butenes $(\mathrm{P} / \mathrm{B})$ molar ratio. One can observe again the advantage of using Theta-1 zeolite for selective propene production: 
Theta-1 restricts butenes formation, which may benefit from shape selectivity effects, although the evolution towards equilibrium is faster than that of $\mathrm{P} / \mathrm{E}$. Next we attempt to rationalize these differences based on the reaction mechanism.

a)

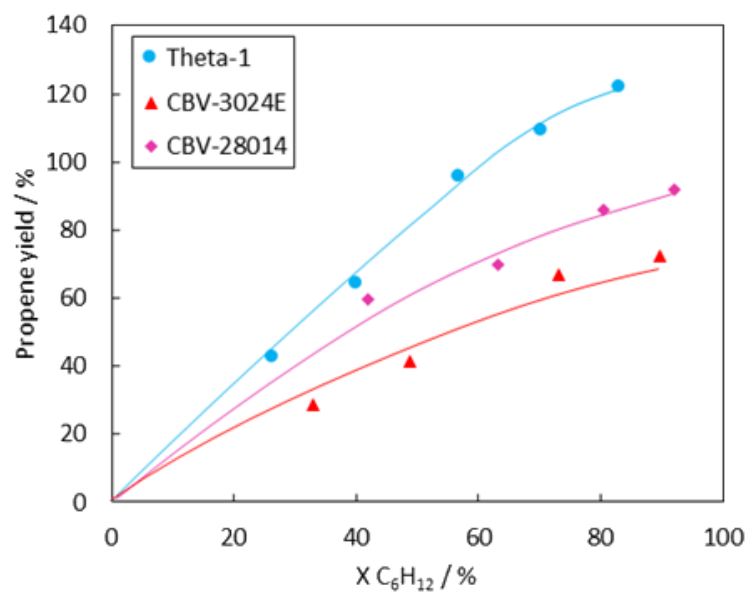

b)

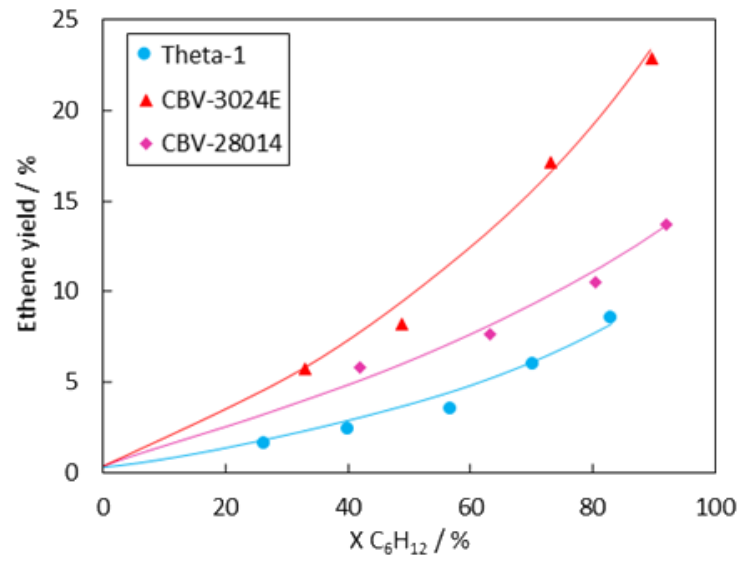

c)

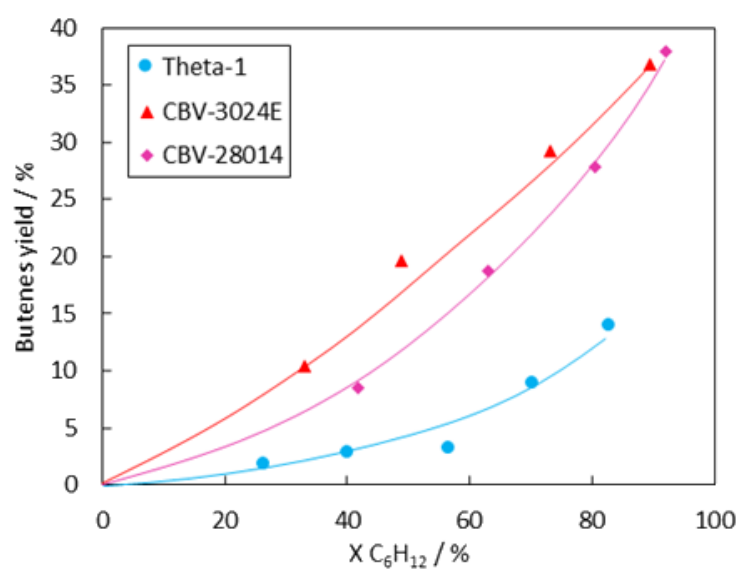

Figure 2. Molar yields to main products vs. conversion of 1-hexene cracking at intermediate feed partial pressure $\left(\mathrm{x}_{0}=0.251\right)$. 
Table 3. Molar yields of 1-hexene catalytic cracking on selected zeolite materials $\left(\mathrm{x}_{0}=\right.$ $0.251)$.

\begin{tabular}{|c|c|c|c|c|c|c|c|c|c|c|c|c|c|c|}
\hline Material & $\begin{array}{c}\mathrm{WHSV}^{-1} \\
/ \mathrm{s}\end{array}$ & $\begin{array}{c}\mathrm{X} \mathrm{C}_{6} \mathrm{H}_{12} \\
1 \%\end{array}$ & $\begin{array}{c}\mathrm{C}_{2} \mathrm{H}_{4} / \\
\%\end{array}$ & $\begin{array}{c}\mathrm{C}_{3} \mathrm{H}_{6} \\
/ \%\end{array}$ & $\begin{array}{c}n-\mathrm{C}_{4} \mathrm{H}_{8} \\
/ \%\end{array}$ & $\begin{array}{c}\mathrm{i}-\mathrm{C}_{4} \mathrm{H}_{8} \\
/ \%\end{array}$ & $\begin{array}{c}\mathrm{C}_{5} \mathrm{H}_{10} \\
/ \%\end{array}$ & $\begin{array}{l}\mathrm{CH}_{4} \\
1 \%\end{array}$ & $\begin{array}{c}\mathrm{C}_{2} \mathrm{H}_{6} \\
/ \%\end{array}$ & $\begin{array}{c}\mathrm{C}_{3} \mathrm{H}_{8} \\
/ \%\end{array}$ & $\begin{array}{c}n-\mathrm{C}_{4} \mathrm{H}_{10} \\
/ \%\end{array}$ & $\begin{array}{c}\mathrm{i}-\mathrm{C}_{4} \mathrm{H}_{10} \\
/ \%\end{array}$ & $\begin{array}{c}\mathrm{C}_{5} \mathrm{H}_{12} \\
1 \%\end{array}$ & $\begin{array}{l}\text { BTX } \\
1 \%\end{array}$ \\
\hline \multirow{5}{*}{ Theta-1 } & 2.5 & 26.4 & 1.6 & 42.5 & 1.5 & 0.4 & 0.4 & 0.04 & 0.04 & 0.04 & 0.00 & 0.00 & 0.00 & 0.03 \\
\hline & 5.0 & 40.1 & 2.4 & 64.2 & 2.2 & 0.7 & 0.6 & 0.06 & 0.06 & 0.10 & 0.00 & 0.00 & 0.00 & 0.12 \\
\hline & 10.0 & 56.8 & 3.5 & 95.5 & 3.1 & 1.2 & 0.5 & 0.06 & 0.07 & 0.16 & 0.00 & 0.01 & 0.00 & 0.08 \\
\hline & 19.9 & 70.4 & 6.0 & 109.3 & 5.8 & 3.1 & 2.5 & 0.08 & 0.10 & 1.60 & 0.01 & 0.03 & 0.00 & 0.32 \\
\hline & 39.8 & 82.9 & 8.5 & 122.1 & 8.7 & 5.2 & 4.4 & 0.11 & 0.13 & 2.70 & 0.04 & 0.09 & 0.02 & 0.44 \\
\hline \multirow{4}{*}{$\begin{array}{l}\text { CBV- } \\
3024 E\end{array}$} & 0.7 & 32.9 & 5.7 & 28.6 & 6.8 & 3.6 & 3.6 & 0.06 & 0.05 & 1.11 & 0.09 & 0.22 & 0.10 & 0.91 \\
\hline & 1.3 & 48.8 & 8.2 & 41.3 & 12.4 & 7.2 & 7.5 & 0.06 & 0.12 & 1.05 & 0.35 & 0.68 & 0.23 & 0.77 \\
\hline & 2.5 & 73.2 & 17.1 & 66.8 & 18.5 & 10.7 & 8.2 & 0.17 & 0.16 & 2.29 & 0.63 & 1.22 & 0.29 & 1.09 \\
\hline & 4.8 & 89.6 & 22.9 & 72.2 & 22.5 & 14.3 & 10.6 & 0.24 & 0.27 & 4.36 & 1.25 & 2.50 & 0.70 & 2.17 \\
\hline \multirow{4}{*}{$\begin{array}{l}\text { CBV- } \\
28014\end{array}$} & 5.0 & 41.8 & 5.8 & 59.4 & 5.7 & 2.7 & 3.0 & 0.04 & 0.03 & 0.06 & 0.00 & 0.00 & 0.00 & 0.06 \\
\hline & 10.0 & 63.1 & 7.7 & 69.6 & 12.1 & 6.6 & 8.6 & 0.05 & 0.03 & 0.86 & 0.03 & 0.05 & 0.02 & 0.18 \\
\hline & 19.9 & 80.4 & 10.5 & 85.9 & 17.3 & 10.5 & 11.8 & 0.06 & 0.04 & 1.09 & 0.07 & 0.13 & 0.06 & 0.28 \\
\hline & 39.8 & 92.1 & 13.7 & 91.8 & 23.9 & 14.9 & 13.6 & 0.10 & 0.07 & 1.67 & 0.17 & 0.34 & 0.14 & 0.42 \\
\hline \multirow{4}{*}{$\begin{array}{l}\text { Treated } \\
\text { Theta-1 }\end{array}$} & 2.5 & 38.0 & 2.0 & 61.2 & 2.0 & 0.6 & 0.5 & 0.08 & 0.04 & 0.08 & 0.00 & 0.00 & 0.00 & 0.06 \\
\hline & 5.0 & 49.9 & 3.1 & 81.1 & 2.8 & 1.0 & 0.9 & 0.06 & 0.06 & 0.85 & 0.00 & 0.01 & 0.00 & 0.10 \\
\hline & 9.6 & 67.3 & 4.3 & 113.2 & 3.3 & 1.5 & 1.0 & 0.06 & 0.08 & 0.30 & 0.00 & 0.00 & 0.00 & 0.12 \\
\hline & 10.0 & 68.8 & 4.8 & 110.3 & 4.7 & 2.2 & 2.0 & 0.07 & 0.09 & 1.04 & 0.01 & 0.00 & 0.00 & 0.28 \\
\hline
\end{tabular}

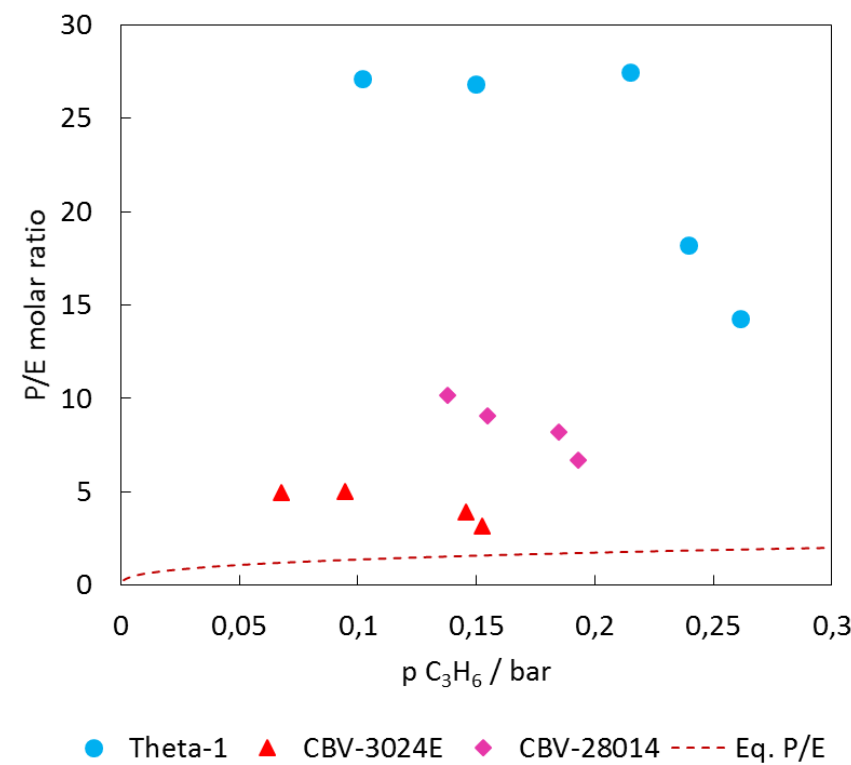

Figure 3. Propene-to-ethene molar ratio $(\mathrm{P} / \mathrm{E})$ upon 1-hexene cracking $\left(\mathrm{x}_{0}=0.251\right)$ and corresponding equilibrium $\mathrm{P} / \mathrm{E}$. 


\subsection{Reaction mechanism and selectivity}

It has been known for long that, thanks to its functional group, olefins are much more reactive than alkanes for acid catalytic cracking (26). More than that, it was observed that cracking rates of olefins are much more sensitive to the chain length of the molecule than those of alkanes (26). Adsorption enthalpy in a homologous series of hydrocarbons on a zeolite increases with chain length thanks to additional van der Waals interactions between the molecules and the solid (31). However, the mechanism of activation of alkanes and alkenes differs: alkanes require evolving through a pentacoordinated carbonium-like transition state (32), which is energetically unfavorable, whereas double bonds in alkenes can be much more easily activated by direct protonation.

Cracking of hexene on acid ZSM-5 zeolites was initially proposed as occurring mainly through an oligomerization-cracking mechanism $(33,34)$. This was based on the observation of different products such as pentenes or heptenes, in addition to significant amounts of ethene and propene, which would be disfavored by monomolecular cracking of 1-hexene. However, more recently, higher selectivities observed on materials with smaller pores, such as SAPO-34 (21) or ZSM-22 (35), and also with ZSM-5 of high $\mathrm{Si} / \mathrm{Al}(36,37)$, have led to consider the mechanism as mainly monomolecular over ZSM-5 as well $(26,36,37)$. Even, the formation of ethene and butenes was proposed to occur through monomolecular cracking over SAPO-34 (21), although this is a particular material given its cage-containing structure accounting for the complex hydrocarbon pool mechanism used to explain related reactions $(38,39)$. Cracking of pentene over ZSM-5 acid zeolites has also been proposed to occur, at least partially, through a monomolecular cracking mechanism under certain conditions $(19,20,40)$. 
The monomolecular cracking of hexene would be favored by fast rates of isomerization, by which isohexene can form and crack conveniently through $\beta$-cleavage involving only secondary carbocations (Type C $\beta$-scission) $(26,35)$. This is illustrated in Scheme 1. Notice that the formation of butene and ethene upon cracking of adsorbed $n$-hexene species would be slower than that from adsorbed isohexene species, as the latter reaction involves tertiary + primary carbenium-like transition states whereas the former would have to occur through less stable secondary + primary carbenium-like species.

In the case of Theta-1, one might expect isomerization rates of 1-hexene to be hindered compared to those over ZSM-5 due to its straight 1D pores. Nevertheless, we have observed comparable hexene isomer distributions on Theta-1 and ZSM-5 materials, both at low and high conversion levels. It is likely, however, that in the case of Theta-1 the conversion of hexene is contributed to a significant extent by pore-mouth catalysis, as has been described when applying this material for isodewaxing (41-43). As a corollary, since isomerization reactions through hydride and alkyl shifts are catalyzed to faster rates than cracking, one would expect that different hexene isomers could also be processed over these materials, as proposed in section 3.5.

One possibility to account for the high selectivity to propene observed over Theta-1 zeolite could be related to differences in solvation and acid strength with respect to ZSM-5 (44). In this regard, Theta-1 might be less effective in stabilizing the formation of butene and ethene through monomolecular cracking of hexenes, directing the conversion to propene. Importantly, the extent of bimolecular reactions (alkylation, oligomerization, cyclization, hydrogen transfer) over Theta-1 zeolite is much more restricted than over the $3 \mathrm{D}$ structure of ZSM-5 with wide pore intersections. This restriction would further decrease the possibilities for butenes and ethene formation from hexenes over Theta-1 zeolite. 


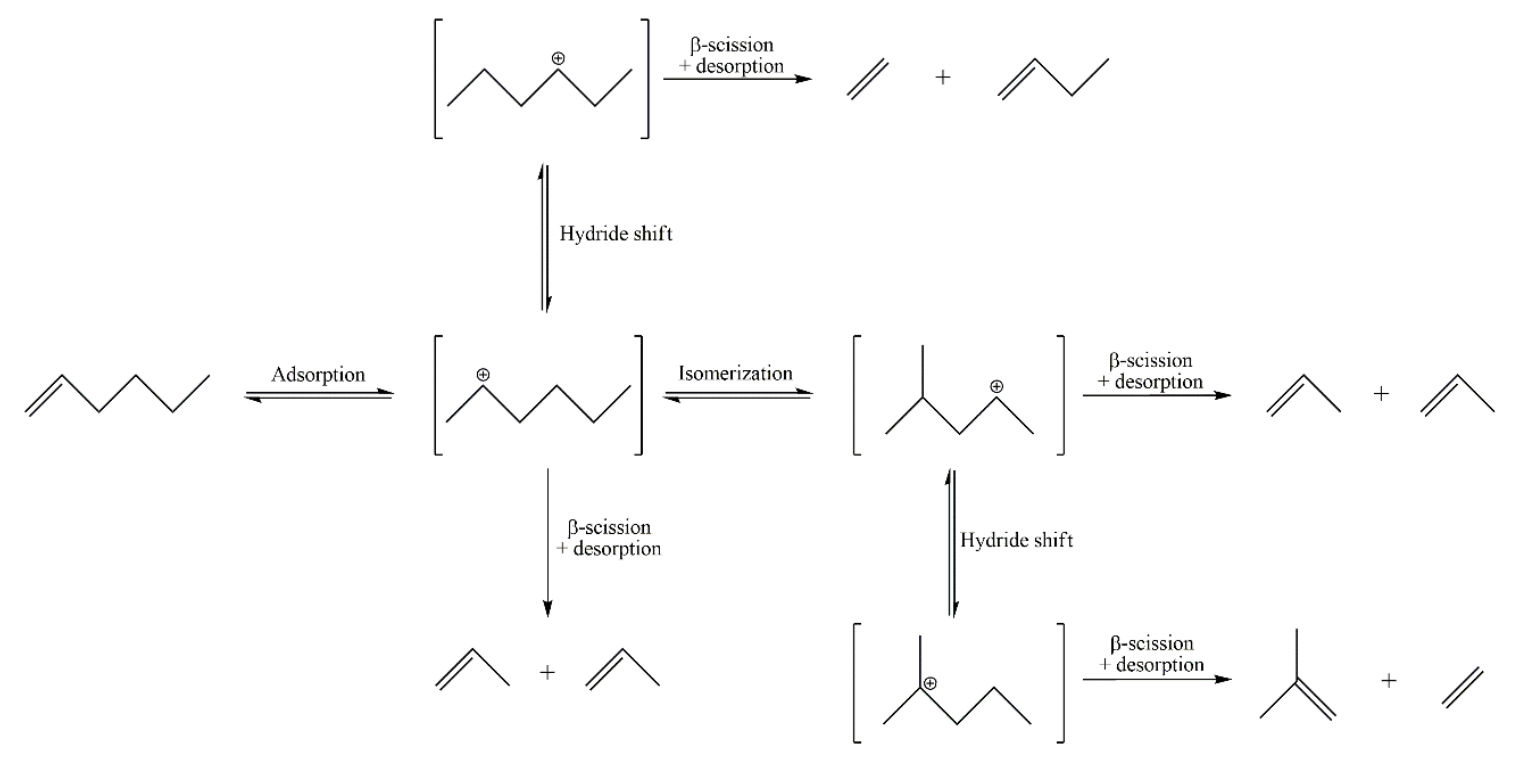

Scheme 1. Main reactions of the monomolecular cracking mechanism of 1-hexene to light olefins on zeolite acid centers.

Overall, the above kinetic results suggest that, at $500{ }^{\circ} \mathrm{C}$ and a feed molar fraction below 0.251, monomolecular cracking of hexene over ZSM-5 and Theta-1 is the predominant mechanism. It explains propene being the main product, $\mathrm{P} / \mathrm{B}$ ratios in great excess over the thermodynamic value, and is consistent with the cracking modes available for hexene and the low surface coverage of the catalyst under these conditions (27). Moreover, in a purely monomolecular cracking, one would expect a constant butenes to ethene ratio $(\mathrm{B} / \mathrm{E})$ of one, at least at short contact times before light olefins interconvert or participate in other reactions $(37,45)$. Indeed, our results show a $\mathrm{B} / \mathrm{E}$ ratio close to one on all samples at low hexene partial pressure. This interpretation is also in agreement with recent observations by other groups $(36,37)$. 


\subsection{Improving Theta-1 zeolite catalyst}

In addition to the aforementioned effects of external and internal diffusion at the pellet level, it must be acknowledged that intracrystal diffusion can impact the observed rates as well. This can lead to inefficient utilization of the crystals and is more likely to have an effect on selectivity in catalysis by zeolites. Koyama et al. simulated different molecules that could intervene in olefin cracking and found that hexyl cations occupy a volume around 116-152 $\AA^{3}$ and hexene isomers are around 140-182 $\AA^{3}$ (35). When these values are assimilated to spheres, the resulting diameters are 6.0-6.6 and 6.4-7.0 $\AA$, respectively. If one compares this value with the crystallographic free diameters of Theta-1 zeolite, 4.6 x $5.7 \AA$ (24), it is clear that the presence of hexene molecules in the zeolite, in addition to those adsorbed on acid sites (28), will hinder the cracking inside Theta-1 channels. On the other hand, ZSM-5 presents a tridimensional pore system compared to the one-dimensional pore system of Theta-1. In fact, in the crossing between straight and sinusoidal channels of ZSM-5 a larger section is created, which would allow entrapping a sphere of $6.36 \AA$ (35). Thus, although Theta-1 zeolite also has 10-MR channels, having a monodimensional pore network could definitely slow down net diffusion rates compared to those in the 3-dimensional ZSM-5 zeolite. This would contribute to CBV-28014 having a much higher apparent TOF than Theta-1. To assess this effect of intracrystal mass transfer limitations and thus optimize Theta- 1 zeolite, we carried out additional experiments as presented below.

Theta-1 material was subjected to the postsynthesis treatment described in 2.1 with the aim to improve its catalytic activity while maintaining its remarkable selectivity. PXRD in Fig. S1 shows preserved crystallinity of the material -which might not be the case with other treatments, e.g. mechanical-, whereas ICP-AES and FTIRS of pyridine do not evidence a large alteration of its acidity (Table S2). Fig. 4 shows some textural 
characteristics of Theta-1 materials. Given the needle-shaped crystals of the parent Theta-1 material, etching becomes more intense along the grooves on the surface and it also leads to abundant pitting spots. Particularly large attack areas are seen to evolve in the mid-section of the large crystals, leading to wider mesopores which eventually cause crystal fragmentation. This is also observed from the $\mathrm{N}_{2}$ adsorption experiments, Fig. 4 c) and d). All the materials present mixed type I isotherms with mesopores. In the parent Theta-1 a few mesopores are present, most likely intercrystalline, which lead to a hysteresis loop. It closes at relative pressure around 0.45 due to the tensile strength effect in mesopores with diameters around $3.8 \mathrm{~nm}$ (46). Over the treated material, the adsorption capacity is notably enhanced at high relative pressures and the hysteresis loop becomes much more vertical, which evidence the development of mesopores. According to the $\mathrm{BJH}$ analysis, these would be centered around $30 \mathrm{~nm}$, in good agreement with the pitting spots observed in the microscope. As a result, mesopore volume is increased by over $300 \%$ in the treated material compared to the parent (Table S1). 

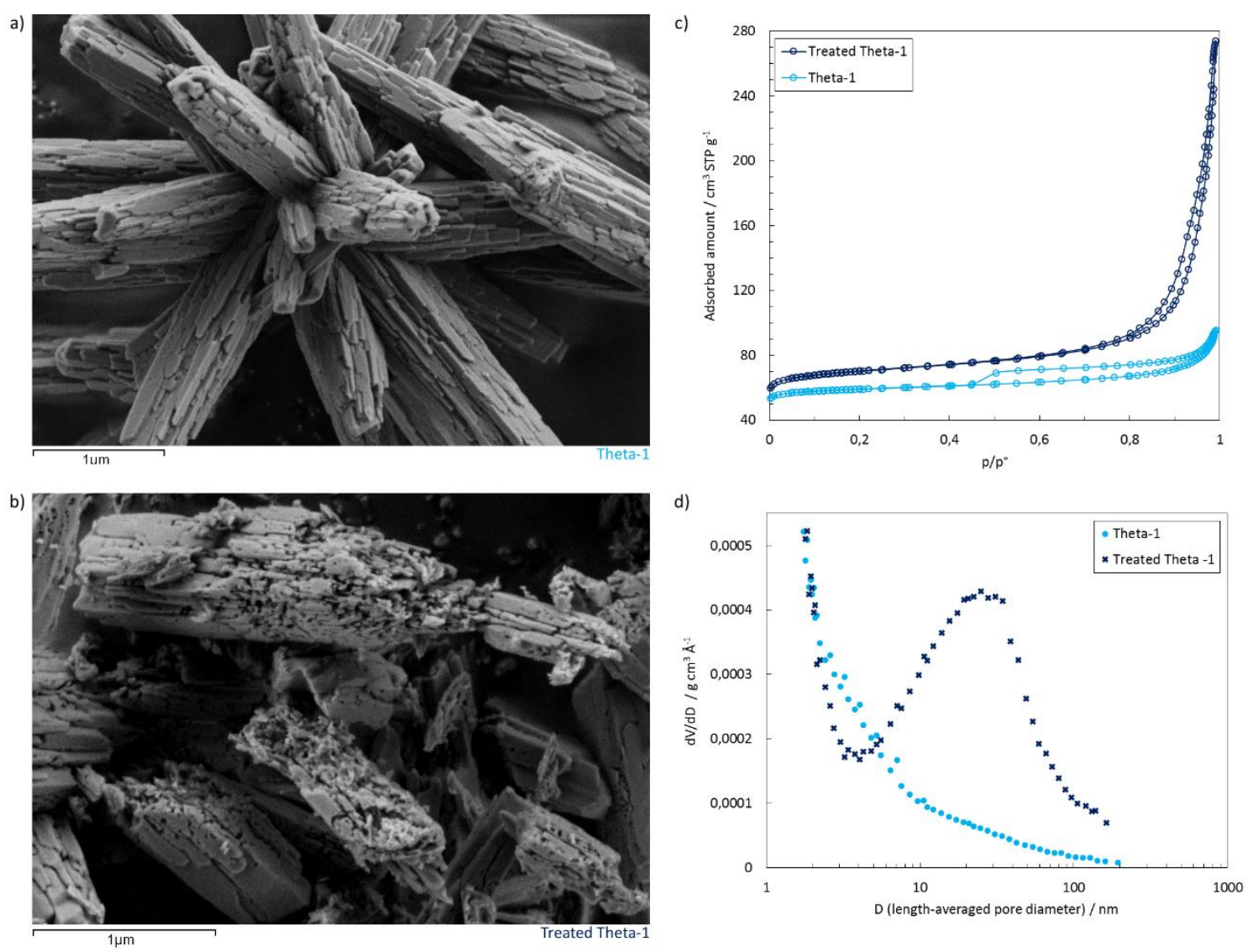

Figure 4. FE-SEM images of a) parent Theta-1 and b) treated Theta-1. c) Nitrogen adsorption-desorption isotherms at $77 \mathrm{~K}$ and d) $\mathrm{BJH}$ analyses of the adsorption branches.

Fig. 5 shows the activity of treated Theta- 1 material. The activity of the material is consistently improved, hence demonstrating that intracrystal diffusion exerts an influence on the observed kinetics of Theta- 1 material. Since the parent Theta- 1 sample has large crystal sizes, the introduction of mesopores leads to shorter intracrystal diffusion lengths and hence improved activity. This is also evidenced by the apparent TOF (Table S3), which is increased by over $50 \%$ upon hierarchization. Finally, referring to Fig. S9, it is observed that the remarkable selectivity of Theta-1 is preserved in the hierarchical material, since its distribution of acid sites remains unaltered, in agreement with our previous discussion. These results would make the industrial 
implementation of Theta-1 even more attractive, for which we propose some possibilities in the next section.
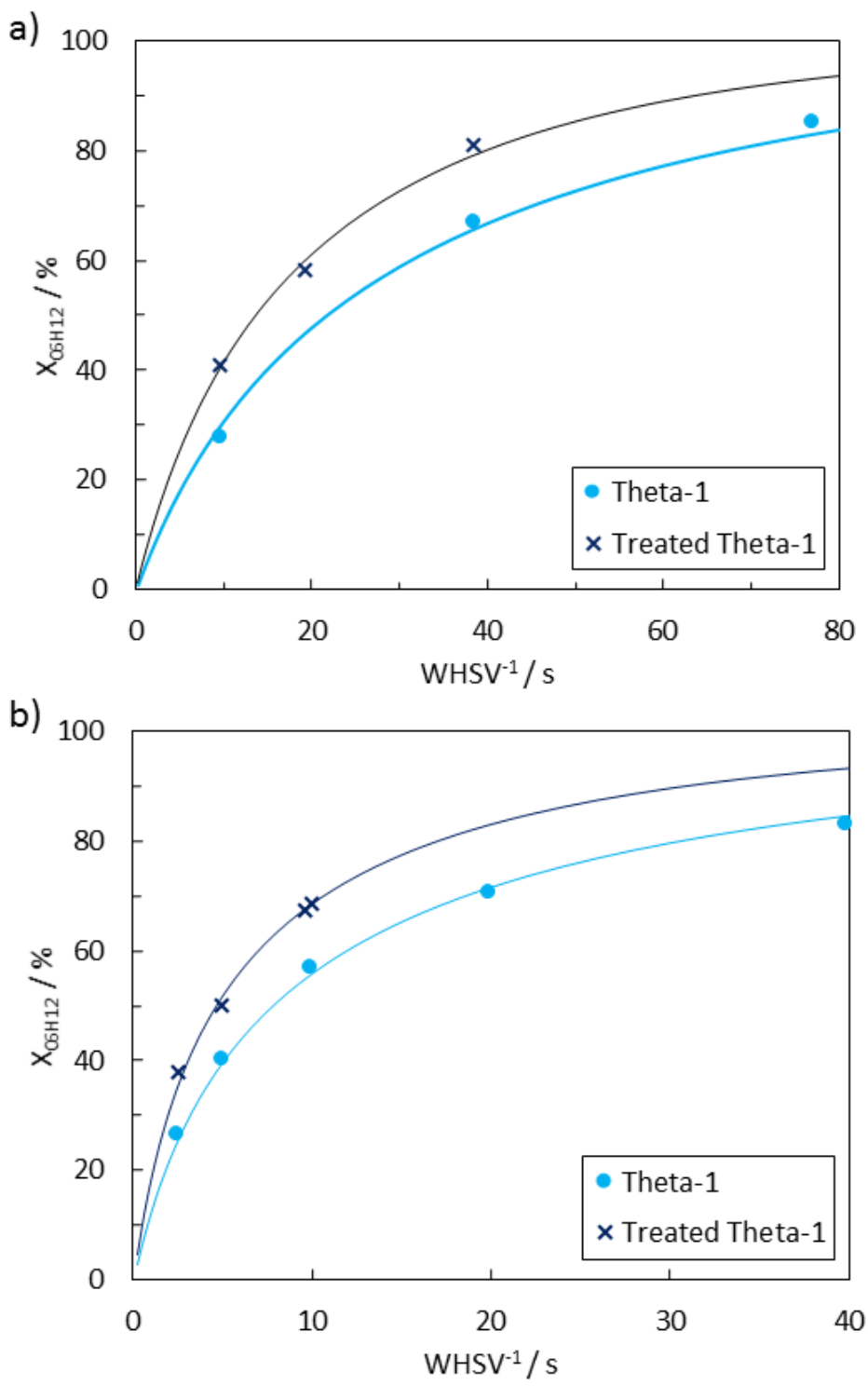

Figure 5. Conversion of 1-hexene vs. contact time on selected zeolites at a) low $\left(\mathrm{x}_{0}=\right.$ $0.065)$, and $\mathrm{b})$ intermediate $\left(\mathrm{x}_{0}=0.251\right)$ feed partial pressures. 


\subsection{Prospective applications in industry}

Given its high selectivity, Theta-1 zeolite positions itself as a new possibility to notably upgrade hexene-containing streams. Being acid, Theta-1 zeolite will isomerize the different hexene molecules and still maintain its high selectivity to propene. In industry one can identify different streams containing important amounts of hexene molecules. Although hexenes are not found in crude oil, they form in processes such as FCC, steam cracking (especially of naphthas, as in the pygas cut), MTO, Fischer-Tropsch, cokers or delayed cokers, metathesis, and so on. In the following some examples are discussed to illustrate the potential of the results found in this work.

We propose that Theta-1 zeolite could be advantageously integrated within an olefin metathesis process to further increase propene production. Olefin metathesis is a propene on purpose technology that supplies about $4 \%$ of the global propene demand (over 4 Mtpy). Scheme 2 shows the main reactions taking place in olefin metathesis of butenes with ethene. Metathesis catalysts contain homogeneous and heterogeneous transition metals of groups VI and VIII. Ethene is co-feed to the process, on the one hand, to react with 2-butene, leading to the preferred metathesis reaction where two propene molecules are obtained. On the other hand, ethene also dilutes butenes and minimizes the undesired reaction between 1- and 2-butenes, which leads to 2-pentenes. 


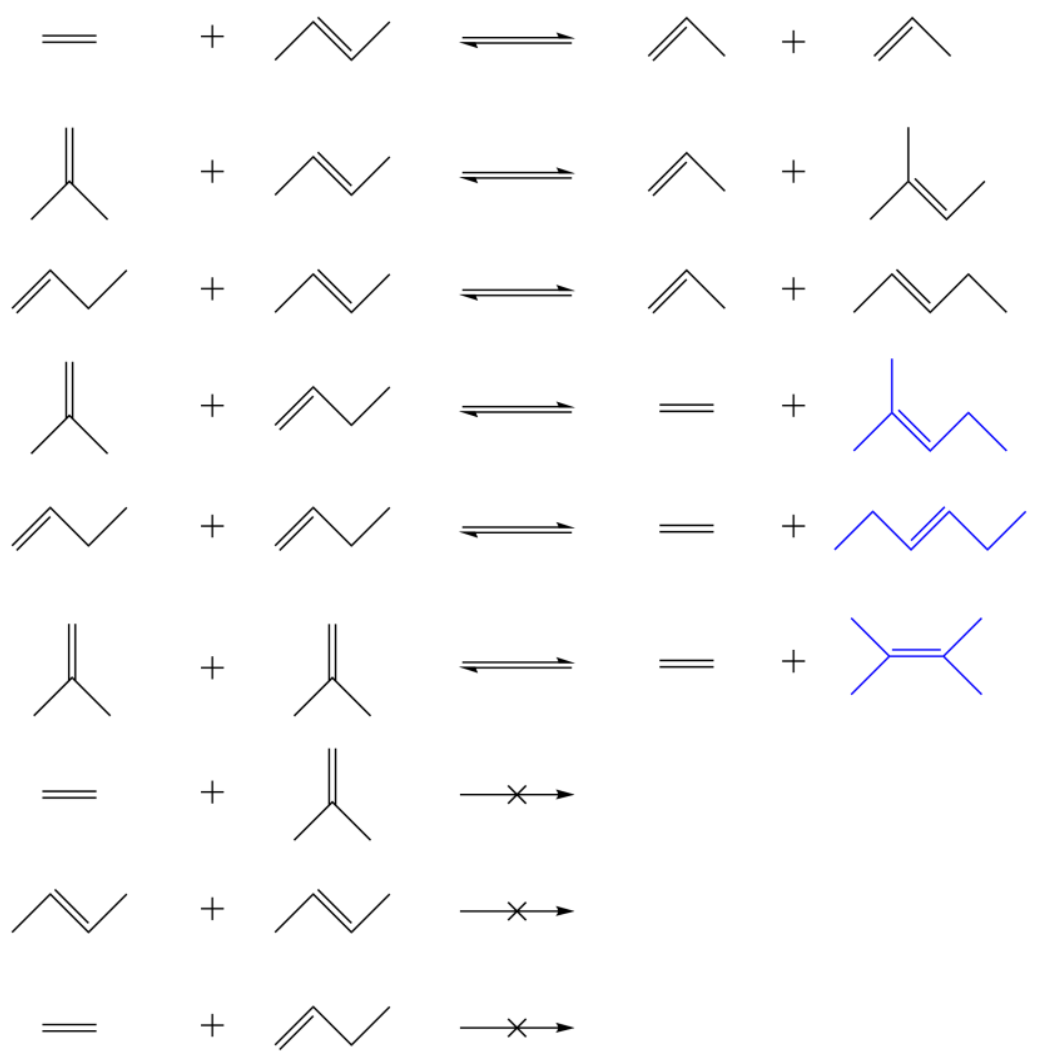

Scheme 2. Main reactions involved in olefin metathesis for on purpose propene production. Hexene isomers are remarked in blue.

As a result, the economics of the process are strongly dependent on the propene/ethene price ratio. In addition, availability of ethene may be limited, particularly in metathesis units integrated in refineries. This has led to propose back-end process schemes that employ isobutene as the $\alpha$-olefin to react with the linear butenes, thus reducing the requirement of ethene (47). These reactions produce isoamylene (by reaction with 2butene) and isohexene (by reaction with 1-butene) along with propene and ethene, respectively. A detailed description of front-end and back-end metathesis process schemes can be found in (48). Isoamylene and isohexene already represent an upgrading of isobutene, as this stream has a high octane number and virtually no sulfur, allowing its incorporation to the gasoline pool. However, thanks to the behavior of Theta-1 as a 
cracking catalyst we could take this upgrading one step further. We propose contacting this mixture containing isoamylene and isohexene with Theta-1 zeolite, as shown in Fig. 6.

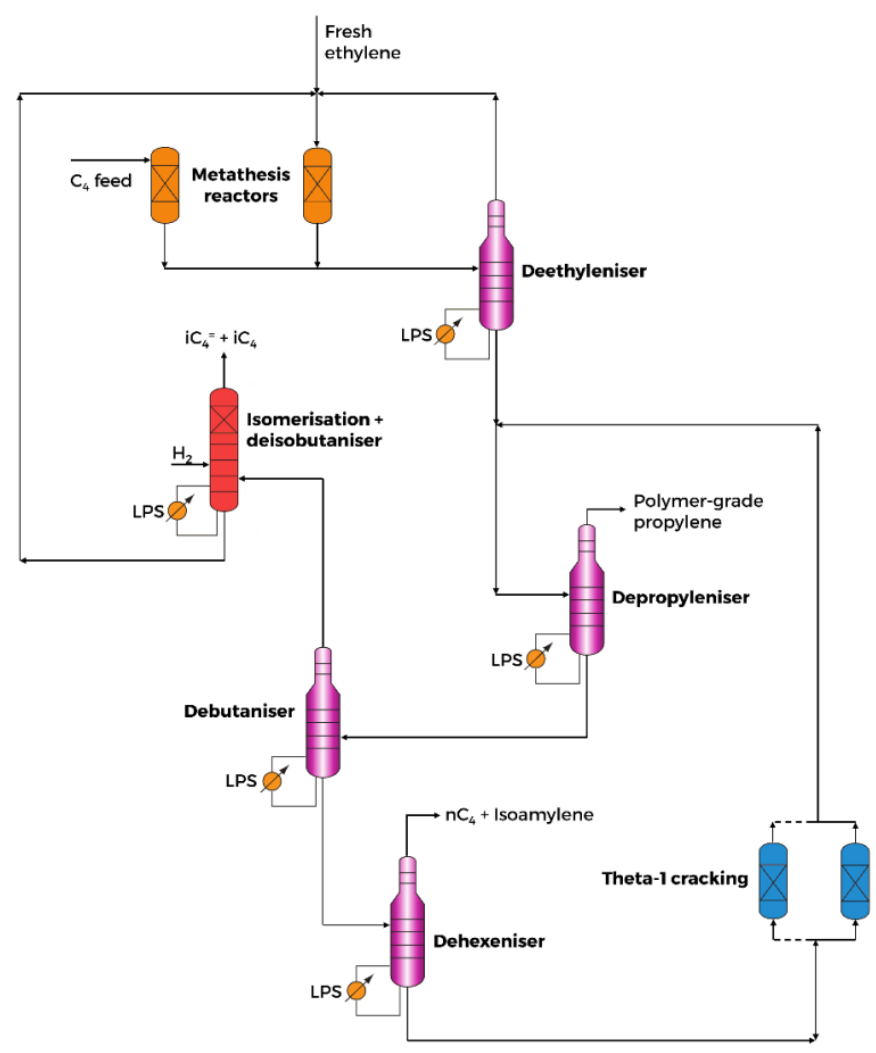

Figure 6. Proposed integration of selective catalytic cracking of 1-hexene along with back-end olefin metathesis (43) for on purpose propene production.

According to this proposal, isohexene would be selectively converted to propene, which would represent an important upgrading step given the current market prices. In its turn, the $\mathrm{C}_{5}=$ olefins would be concentrated in the effluent stream, since their cracking would rather require an oligomerization step to proceed at fast rate, which is much hindered within the pores of Theta- 1 zeolite. We are currently working to demonstrate this proposal. This would allow its use downstream for production of tert-amyl methyl ether 
(TAME), a valuable oxygenated gasoline additive, increasing its value relative to direct blending in the gasoline pool. We are currently working on demonstrating this proposal.

One of the virtues of metathesis is that no paraffins are produced in the process. By contrast, olefin cracking would normally increase the amount of paraffinic molecules by hydrogen transfer reactions. It is very remarkable that, in the case of cracking 1-hexene on Theta-1 zeolite, only small amounts of propane are produced thanks to the important restriction of hydrogen transfer on this catalyst. Fig. S10 shows the propane to propene ratio obtained upon cracking on ZSM-5 and Theta-1 zeolites as a function of conversion. Remarkably, with Theta-1 zeolite propene concentration exceeds $98.5 \%$ among the $\mathrm{C}_{3}$ products $\left(\mathrm{C}_{3}\right.$ olefinicity), which would easily turn into over $99.5 \%$ upon mixing with metathesis-derived propene (polymer-grade propene specification usually ranges from 97 to $99.5 \%$ ), as shown in Table 4. These results would have enormous consequences from the process standpoint: when employing Theta-1 zeolite, even at very high conversion, the product could satisfy polymer-grade specifications, requiring only a carbon number fractionation instead of a costly propene/propane splitter. Regarding the technology most appropriated to implement this olefin cracking, although an exhaustive study of deactivation and regeneration would be mandatory, lifetimes in the range of hours could allow process schemes with lower operating costs than an FCC-type reactor, such as lead-lag configurations of fixed beds. 
Table 4. Calculated composition of propene product in the scheme in Fig. 6.

\begin{tabular}{|c|c|}
\hline $\begin{array}{c}\text { Metathesis } \mathrm{C}_{3}=\text { effluent / } \\
\text { Theta- } 1 \text { cracking } \mathrm{C}_{3}=\text { effluent }\end{array}$ & $\begin{array}{c}\text { Propane concentration } \\
\text { in product } / \%\end{array}$ \\
\hline 50 & 0.05 \\
20 & 0.12 \\
10 & 0.23 \\
5 & 0.42 \\
3 & 0.63 \\
\hline Polymer-grade $\mathrm{C}_{3}{ }^{=}$spec. & $<0.5$ \\
\hline
\end{tabular}

*Assuming a propane content in Theta-1 effluent of $2.5 \%$.

Other possibilities for cracking hexenes with Theta-1 zeolite would be its integration into a metathesis unit of butenes producing ethene and hexene (49), or propene and hexene (50). In this case, the molar propene to ethene ratio would be around 2 , which is already an interesting value towards commercialization. Another possibility could be its use in an ethene to propene technology (51). At present, ethene to propene can be achieved by ethene dimerization and subsequent metathesis of the formed butenes.

\section{Concluding remarks}

In this work we have reported the high activity and excellent selectivity of Theta-1 zeolite in the cracking of 1-hexene to propene, outperforming the yields achievable with commercial ZSM-5 zeolites. This is possible thanks to a combination of shape selectivity by the one-dimensional $10-\mathrm{MR}$ pore system of Theta-1 zeolite and a narrow distribution of acid sites. Among ZSM-5 samples, a high $\mathrm{Si} / \mathrm{Al}$ ratio was found favorable to increase the selectivity to propene by limiting its further reaction towards aromatics. Over Theta-1, an exceptionally high selectivity to propene is attained, which stems from its distinct structure directing the catalysis to this product and suppressing bimolecular reactions compared to ZSM-5 zeolite. 
We have also demonstrated that hexene cracking on acid zeolites is prone to both external and internal diffusional limitations. Moreover, intracrystal diffusion limitations can be present as well even in the sub-micron range. In the case of Theta-1 material, these were notably alleviated by adjusting the length of its channels without affecting its selectivity. These findings have great implications at the industrial scale, where TONbased catalysts could be advantageously used in the upgrading of hexene-rich streams for on purpose propene production. The integration with metathesis units would be an interesting possibility, potentially avoiding the use of energy-intensive propene superfractionators.

\section{Nomenclature}

Variables and parameters

c $\quad$ Molar concentration $/ \mathrm{mol} \mathrm{m}^{-3}$

d Diameter / $\mathrm{m}$

D Diffusivity $/ \mathrm{m}^{2} \mathrm{~s}^{-1}$

F $\quad$ Feed molar flow / $\mathrm{mol} \mathrm{s}^{-1}$

$\mathrm{k}_{1} \quad$ Apparent first order kinetic constant $/ \mathrm{mol} \mathrm{kg}^{-1} \mathrm{bar}^{-1} \mathrm{~s}^{-1}$

$\mathrm{k}_{\mathrm{n}} \quad$ Apparent kinetic constant $/ \mathrm{mol} \mathrm{kg}^{-1} \mathrm{bar}^{-\mathrm{n}} \mathrm{s}^{-1}$

$\mathrm{k}_{\mathrm{c}} \quad$ External mass transfer coefficient $/ \mathrm{m} \mathrm{s}^{-1}$

M Molar mass $/ \mathrm{kg} \mathrm{mol}^{-1}$

n Order of reaction

$\mathrm{p} \quad$ Absolute partial pressure / bar

$\mathrm{P} \quad$ Total absolute pressure / bar

$\mathrm{r} \quad$ Reaction rate $/ \mathrm{mol} \mathrm{kg}^{-1} \mathrm{~s}^{-1}$

R Radius

$\mathrm{R}^{2} \quad$ Coefficient of determination $\left(\mathrm{R}^{2}=1-\mathrm{RSS} / \mathrm{TSS}\right)$

Re Reynolds number

RMSE Root-mean-square error, RMSE $=\left(\text { mean }\left[\left(\mathrm{X}_{\text {observed }}-\mathrm{X}_{\text {calculated }}\right)^{2}\right]\right)^{1 / 2}$

$\mathrm{S} \quad$ Specific surface $/ \mathrm{m}^{2} \mathrm{~kg}^{-1}$

Sc Schmidt number 


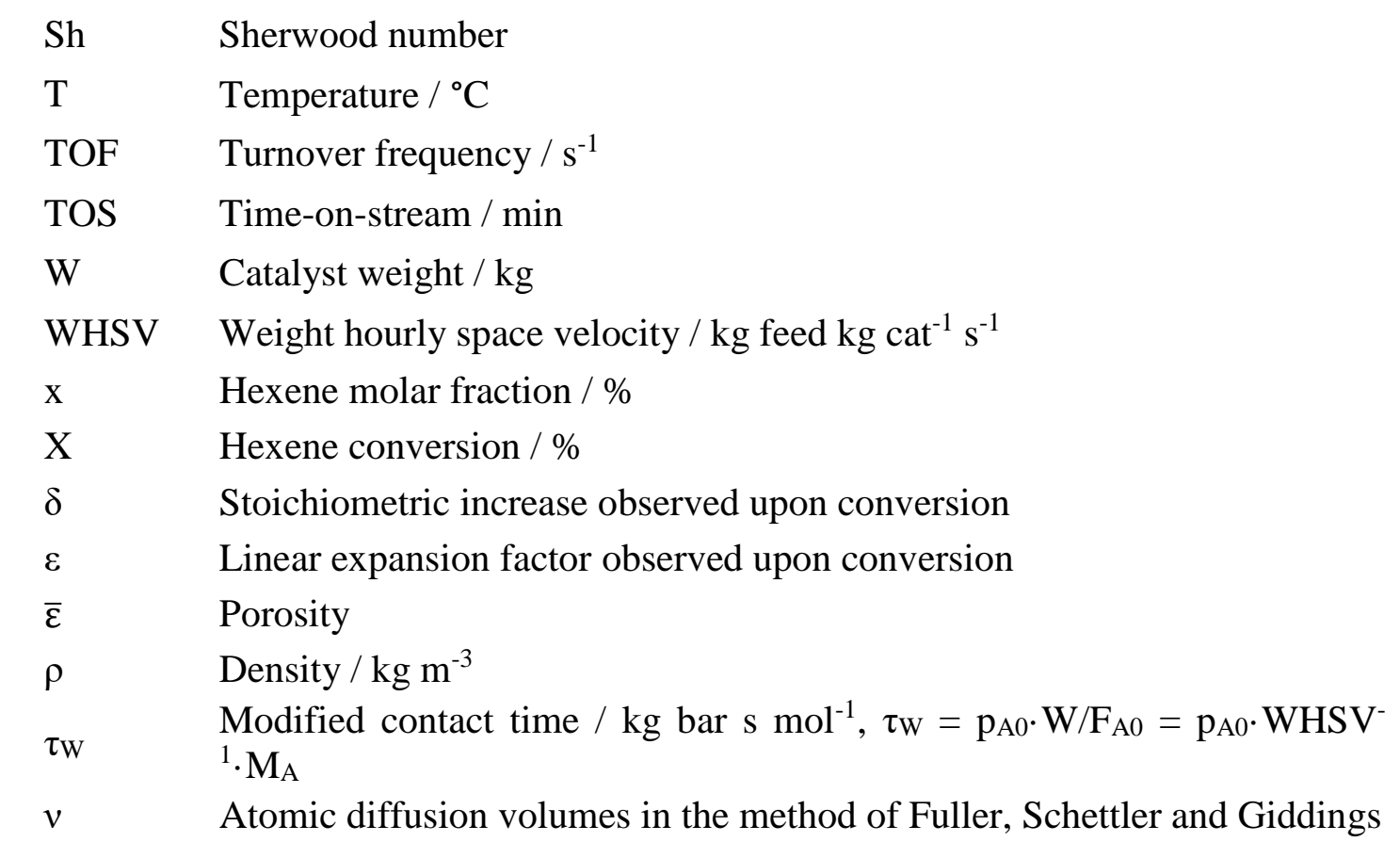

\section{Subindices}

$\begin{array}{ll}0 & \text { Initial (feed conditions) } \\ \text { A } & \text { Hexene, incl. isomers } \\ \text { B } & \text { Helium } \\ \text { K } & \text { Knudsen } \\ \text { p } & \text { Pellet } \\ \text { T } & \text { Transition }\end{array}$

\section{References}

1. M. Bender, ChemBioEng Rev., 2014, 1, 136-147.

2. C. Wheeler, in Global Chemistry Industry Update; Houston Business Roundtable; 2016.

3. A. Akah, M. Al-Ghrami, Appl. Petrochem. Res. 2015, 5, 377-392.

4. A. Corma, E. Corresa, Y. Mathieu, L. Sauvanaud, S. Al-Bogami, M. Al-Ghrami, A. Bourane, Catal. Sci. Technol., 2017, 7, 12-46.

5. J. Sun, C. Liu, Y. Wang, K. Martin, P. Venkitasubramanian, US20150239800, 2015.

6. N. Rahimi, R. Karimzadeh, Appl. Catal. A, 2011, 398, 1-17.

7. A. Corma, J. Mengual, P. J. Miguel, Appl. Catal. A, 2012, 417-418, 220-235.

8. A. Corma, J. Mengual, P. J. Miguel, Appl. Catal. A, 2012, 421-422, 121-134. 
9. A. Corma, J. Mengual, P. J. Miguel, Appl. Catal. A, 2013, 460-461, 106-115.

10. R. Bastiani, Y. L. Lam, C. A. Henriques, V. Teixeira da Silva, Fuel, 2013, 107, 680687.

11. A. I. Hussain, A. M. Aitani, M. Kubů, J. Čejka, S. Al-Khattaf, S. Fuel, 2016, 167, 226-239.

12. Y. Wang, T. Yokoi, S. Namba, J. N. Kondo, T. Tatsumi, Appl. Catal. A, 2015, 504, 192-202.

13. Y. Wang, T. Yokoi, S. Namba, J. N. Kondo, T. Tatsumi, J. Catal., 2016, 333, 17-28.

14. X. Tang, H. Zhou, W. Qian, D. Wang, Y. Jin, F. Wei, Catal. Lett., 2008, 125, 380385.

15. E. Epelde, A. G. Gayubo, M. Olazar, J. Bilbao, A. T. Aguayo, Chem. Eng. J., 2014, 251, 80-91.

16. J. Li, H. Ma, Q. Sun, W. Ying, D. Fang, Fuel Process. Technol., 2015, 134, 32-38.

17. Y. Iwase, Y. Sakamoto, A. Shiga, A. Miyaji, K. Motokura, T. Koyama, T. Baba, J. Phys. Chem. C, 2012, 116, 5182-5196.

18. P. Arudra, T. I. Bhuiyan, M. N. Akhtar, A. M. Aitani, S. Al-Khattaf, H. Hattori, ACS Catal., 2014, 4, 4205-4214.

19. A. Miyaji, Y. Sakamoto, Y. Iwase, T. Yashima, R. Koide, K. Motokura, T. Baba, J. Catal., 2013, 302, 101-114.

20. L. F. Lin, S. F.Zhao, D. W. Zhang, H. Fan, Y. M. Liu, M. Y. He, ACS Catal., 2015, 5, 4048-4059.

21. Z. Nawaz, X. Tang, J. Zhu, F. Wei, S. Naveed, Chin. J. Catal., 2009, 30, 10491057.

22. R. Le Van Mao, A. Muntasar, H. T. Yan, Q. Zhao, Catal. Lett., 2009, 130, 86-92.

23. H. Long, X. Wang, W. Sun, X. Guo, Catal. Lett., 2008, 126, 378-382.

24. C. Baerlocher, L. B. McCusker, Database of Zeolite Structures, http://www.izastructure.org/databases/.

25. C. A. Emeis, J. Catal,. 1993, 141, 347-354.

26. J. S. Buchanan, J. G. Santiesteban, W. O. Haag, J. Catal., 1996, 158, 279-287.

27. A. Corma, J. Mengual, P. J. Miguel, J. Catal., 2015, 330, 520-532.

28. T. Masuda, Catal. Surv. Asia, 2003, 7, 133-144.

29. M. E. Davis, R. J. Davis, Fundamentals of chemical reaction engineering; McGrawHill: 2003.

30. S. Mitchell, N. Michels, J. Perez-Ramirez, Chem. Soc. Rev., 2013, 42, 6094-6112.

31. B. A. De Moor, M. Reyniers, O. C. Gobin, J. A. Lercher, G. B. Marin, J. Phys. Chem. C, 2011, 115, 1204-1219. 
32. S. Kotrel, H. Knözinger, B. C. Gates, B. C. Microp. Mesop. Mat., 2000, 35-36, $11-$ 20.

33. J. Abbot, B. W. Wojciechowski, Can. J. Chem. Eng., 1985, 63, 462-469.

34. W. L. Schuette, A. E. Schweizer, in Bifunctionality in catalytic cracking catalysis; M. L. Occelli, P. O'Connor (Eds.); Studies in Surface Science and Catalysis 134 Fluid Catalytic Cracking V; Elsevier: 2001.

35. T. Koyama, Y. Hayashi, H. Horie, S. Kawauchi, A. Matsumoto, Y. Iwase, Y. Sakamoto, A. Miyaji, K. Motokura, T. Baba, Phys. Chem. Chem. Phys., 2010, 12, 2541-2554.

36. X. Huang, D. Aihemaitijiang, W. Xiao, Chem. Eng. J., 2015, 280, 222-232.

37. L. Ying, J. Zhu, Y. Cheng, L. Wang, X. Li, J. Ind. Eng. Chem., 2016, 33, 80-90.

38. Z. Li, J. Martinez-Triguero, P. Concepcion, J. Yu, A. Corma, Phys. Chem. Chem. Phys., 2013, 15, 14670-14680.

39. P. Tian, Y. Wei, M. Ye, Z. Liu, ACS Catal., 2015, 5, 1922-1938.

40. O. Bortnovsky, P. Sazama, B. Wichterlova, Appl. Catal. A, 2005, 287, 203-213.

41. J. A. Martens, W. Souverijns, W. Verrelst, R. Parton, G. F. Froment, P. A. Jacobs, Angew. Chem. Int. Ed., 1995, 34, 2528-2530.

42. J. A. Martens, G. Vanbutsele, P. A. Jacobs, J. Denayer, R. Ocakoglu, G. Baron, J. A. Muñoz Arroyo, J. Thybaut, G. B. Marin, Catal. Today, 2001, 65, 111-116.

43. J. F. Denayer, A. R. Ocakoglu, W. Huybrechts, J. A. Martens, J. W. Thybaut, G. B. Marin, G. V. Baron, Chem. Commun., 2003, 1880-1881.

44. R. Gounder, E. Iglesia, Chem. Commun., 2013, 49, 3491-3509.

45. R. Zhang, Z. Wang, H. Liu, Z. Liu, G. Liu, X. Meng, Appl. Catal. A, 2016, 522, 165-171.

46. J. C. Groen, L. A. A. Peffer, J. Pérez-Ramírez, Microp. Mesop. Mater., 2003, 60, 117.

47. R. J. Gartside, M. I. Greene, US7214841 B2, 2007.

48. R. J. Gartside, M. I. Greene, PTQ, 2006, Q2, 1-8.

49. R. J. Gartside, US6727396 B2, 2004.

50. P. Schwab, R. Schulz, S. Huber, US20020002317 A1, 2002.

51. S. Follmann, S. Ernst, New J. Chem., 2016, 40, 4414-4419. 


\section{Supplementary information}

Powder X-ray diffraction patterns (Fig. S1) and SEM images (Fig. S2) of the catalysts used, textural properties (Table S1) and acidity measurements (Table S2), pyridine-IR spectra (Fig. S3), conversion vs. modified contact time (Fig. S4), transport limitations (Table S3), equilibrium calculations (Fig. S5), product yields at low partial pressure (Table S4), light olefin yields at low partial pressure (Fig. S6), propene to ethene ratio at low partial pressure (Fig. S7), propene to butenes ratio (Fig. S8), product yields from treated Theta-1 (Table S9), and propane to propene ratio (Fig. S10).

\section{Acknowledgements}

Financial support by the Ministerio de Economía y Competitividad of Spain (MINECO) through the project CTQ2015-70126-R is gratefully acknowledged. V. Blay thanks the support from the Valencian Ministry of Education.

GRAPHICAL ABSTRACT (1 column) 

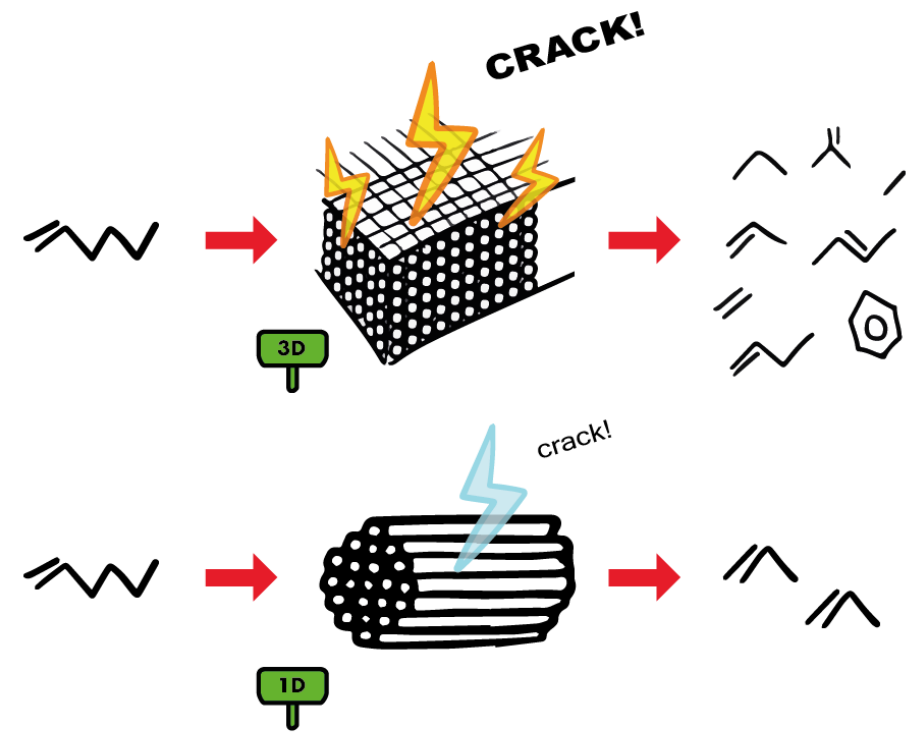